\title{
Atividade Antimicrobiana Dos Óleos Essenciais de Origanum vulgare L. e Rosmarinus officinalis $L$. Frente a Inoculo Misto de Bactérias Contaminantes de Hortaliças Minimamente Processadas
}

Isabella de Medeiros Barbosa (I), Kataryne Árabe Rimá de Oliveira (I), José Alberto da Costa Medeiros (I), Jossana Pereira de Sousa (II), Geany Targino de Souza (I), Maria Lucia da Conceição (I), Evandro Leite de Souza (I)

(I) UFPB - Universidade Federal da Paraíba (Cidade Universitária - João Pessoa - PB - Brasil CEP: 58051-900), (II) UFPE - Universidade Federal de Pernambuco (Cidade Universitária -

Recife - PE - Brasil - CEP: 50670-901)

\section{Resumo}

Considerando a ocorrência de Doenças de Origem Alimentar (DOA) pelo consumo de hortaliças minimamente processadas (HMP) contaminadas, principalmente, por bactérias psicrotróficas e a possibilidade destes microrganismos tornarem-se resistentes à sanitizantes convencionais utilizados na indústria de alimentos, tem sido motivada a pesquisa por novos compostos com ação antimicrobiana. Por isso, o objetivo do presente trabalho foi avaliar o efeito antimicrobiano dos óleos essenciais de Origanum vulgare L. (OEOV) e Rosmarinus officinalis L. (OERO), isolados e combinados, na inibição do crescimento de bactérias contaminantes de HMP, quando ensaiadas em inóculo misto. Os óleos essenciais foram obtidos da empresa Sigma-Aldrich Brasil Ltda. Como microrganismos teste foram utilizados cepas tipo padrão de Listeria monocytogenes ATCC 7644, Pseudomonas fluorescens ATCC 11253 e Aeromonas hydrophila INCQS 7966. Para a avaliação do efeito inibitório dos óleos essenciais foi determinada a Concentração Inibitória Mínima (CIM), utilizando a técnica de macrodiluição em caldo. Após o período de

\footnotetext{
Referência:

Isabella de Medeiros Barbosa, Kataryne Árabe Rimá de Oliveira, José Alberto da Costa Medeiros, Jossana Pereira de Sousa (II), Geany Targino de Souza, Maria Lucia da Conceição, Evandro Leite de Souza. Atividade Antimicrobiana Dos Óleos Essenciais de Origanum vulgare L. e Rosmarinus officinalis L. Frente a Inoculo Misto de Bactérias Contaminantes de Hortaliças Minimamente Processadas. In: Anais do 12 Congresso Latinoamericano de Microbiologia e Higiene de Alimentos - MICROAL 2014 [= Blucher Food Science Proceedings, num.1, vol.1]. São Paulo: Editora Blucher, 2014. 
incubação $\left(37^{\circ} \mathrm{C} / 24 \mathrm{~h}\right)$ a menor concentração dos óleos essenciais capaz de inibir o crescimento microbiano foi considerada como a CIM. Além disso, foi determinada a Concentração Inibitória Fracional (CIF), pelo método de Checkerboard, que avalia o efeito inibitório das substâncias-teste em combinação e em diferentes concentrações. Os valores encontrados para a CIM do OEOV e do OERO foram, respectivamente, $0,6 \mu 1 / \mathrm{mL}$ e $5 \mu 1 / \mathrm{mL}$, o que representa um considerável efeito inibitório. Enquanto o valor da CIF foi 0,75 , sugerindo uma interação aditiva entre os óleos essenciais avaliados. Os resultados obtidos demonstram que o OEOV e o OERO possuem capacidade de inibição do crescimento de bactérias contaminantes de HMP quando testados frente ao inóculo misto dessas bactérias, sugerindo que os mesmos sejam utilizados pela indústria de alimentos como sanitizantes, com destaque para o seu uso combinado, em concentrações sub-inibitórias, de modo a possivelmente reduzir o impacto sensorial na HMP e, consequentemente, melhorar a sua aceitação pelos consumidores.

Palavras-Chave: Alecrim, Hortaliças Minimamente Processadas, Inóculo misto, Óleos essenciais, Orégano

Agência de Fomento: Conselho Nacional de Desenvolvimento Científico e Tecnológico 